\title{
Co-existing spinal intradural ependymal cyst and sacral tarlov cyst in adult-onset tethered cord syndrome with syringomyelia: Case report and literature review
}

\author{
Hamid H. Rai \\ Aga Khan University \\ Muhammad F. Khan \\ Aga Khan University \\ Ather Enam \\ Aga Khan University, ather.enam@aku.edu \\ Imtiaz Hashmi \\ Aga Khan University, imtiaz.hashmi@aku.edu
}

Follow this and additional works at: https://ecommons.aku.edu/pakistan_fhs_mc_surg_neurosurg

Part of the Neurology Commons, Neurosurgery Commons, and the Surgery Commons

\section{Recommended Citation}

Rai, H. H., Khan, M. F., Enam, A., Hashmi, I. (2016). Co-existing spinal intradural ependymal cyst and sacral tarlov cyst in adult-onset tethered cord syndrome with syringomyelia: Case report and literature review. Surgical Neurology International, 7(Suppl 25), S708-S710.

Available at: https://ecommons.aku.edu/pakistan_fhs_mc_surg_neurosurg/214 


\title{
Co-existing spinal intradural ependymal cyst and sacral Tarlov cyst in adult-onset tethered cord syndrome with syringomyelia: Case report and literature review
}

\author{
Hamid H. Rai, Muhammad F. Khan ${ }^{1}$, Syed Ather Enam ${ }^{1}$, Imtiaz Hashmi ${ }^{1}$ \\ Department of Surgery, Section of Neurosurgery, Medical College, Aga Khan University, ${ }^{1}$ Department of Surgery, Section of Neurosurgery, Aga Khan University \\ Hospital, Karachi, Pakistan \\ E-mail: Hamid H. Rai - hamidhussainrai@hotmail.com; Muhammad F. Khan -dr.mfaheemkhan@gmail.com; Syed Ather Enam - ather.enam@aku.edu; \\ *Imtiaz Hashmi - imtiaz.hashmi@aku.edu \\ *Corresponding author \\ Received: 23 June $16 \quad$ Accepted: 26 July $16 \quad$ Published: 22 September 16
}

\begin{abstract}
Background: Synchronous spinal intradural ependymal cysts and sacral Tarlov cysts in adult onset tethered cord syndrome are extremely rare.

Case Description: A 23-year-old male presented with back pain radiating into both lower extremities, accompanied by acute onset of gait difficulty and sphincter dysfunction. Magnetic resonance imaging identified a low lying conus medullaris, syringomyelia with septations extending from $\mathrm{T} 12$ to $\mathrm{S} 1$, a tethered cord, and a thickened filum terminale with a sacral Tarlov cyst. The patient underwent a L3-4 laminectomy for decompression of syringomyelia and excision/biopsy of a space occupying lesion along with S1-2 laminectomy for cord untethering and Tarlov cyst fenestration. Postoperative histopathology confirmed that the lesion was an ependymal cyst. Clinically, patient showed marked improvement in the neurological status.

Conclusion: Simultaneous decompressive laminectomy of L3-4 and S1-2 effectively decompressed the syringomyelia while allowing for excision/biopsy of a space occupying lesion at the former and untethering and Tarlov cyst fenestration at the latter levels.
\end{abstract}

Key Words: Adult tethered cord syndrome, ependymal cyst, Tarlov cyst

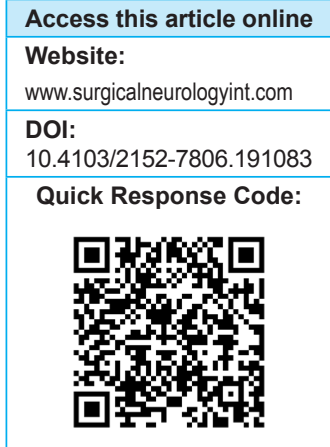

\section{INTRODUCTION}

Tethered cord syndrome (TCS), a form of spinal dysraphism, is defined by a low lying conus medullaris that is tethered by a thickened filum terminale. Because acute symptomatic presentation in adults with TCS is rare, TCS diagnosis is often substantially delayed.

Ependymal cysts, rare benign neuroepithelial congenital lesions that are typically located in the paraventricular white matter (frontal/parietal lobes), are only rarely encountered in the spine. Gross total resection (GTR) may only be possible in $28 \%$ of the patients with intramedullary ependymal cysts, and may even be difficult to those located elsewhere. ${ }^{[3]}$ Therefore, surgery may involve just decompression and cyst subarachnoid shunt placement, and not complete removal.

Tarlov perineural cysts comprise collections of

This is an open access article distributed under the terms of the Creative Commons Attribution-NonCommercial-ShareAlike 3.0 License, which allows others to remix, tweak, and build upon the work non-commercially, as long as the author is credited and the new creations are licensed under the identical terms.

For reprints contact: reprints@medknow.com

How to cite this article: Rai HH, Khan MF, Enam SA, Hashmi I. Co-existing spinal intradural ependymal cyst and sacral Tarlov cyst in adult-onset tethered cord syndrome with syringomyelia: Case report and literature review. Surg Neurol Int 2016;7:S708-10.

http://surgicalneurologyint.com/Co-existing-spinal-intradural-ependymal-cyst-andsacral-Tarlov-cyst-in-adult-onset-tethered-cord-syndrome-with-syringomyelia:-

Case-report-and-literature-review/ 
cerebrospinal fluid (CSF) located between the endoneurium and perineurium of the nerve root sheath near the dorsal root ganglion. Although Tarlov cysts are incidental findings in 4.6-9\% of magnetic resonance imaging (MRI) scans, $1 \%$ of sacral lesions become symptomatic due to local compression, causing local pain, radiculopathy, and incontinence..$^{[1,4]}$

Here, we present a 23-year-old patient with a thoracolumbar intradural ependymal cyst and sacral Tarlov cyst with adult TCS/syringomyelia, which was treated successfully with microsurgical decompression (e.g. laminectomy L3-4 and S1-2) and shunting.

\section{CASE REPORT}

Case presentation, examination, and investigation A 23-year-old male presented with 2-4 weeks of worsening left greater than right-sided lower back pain, radiating bilaterally into both lower extremities, accompanied by 4 days of urinary overflow incontinence. On neurological examination, the patient exhibited decreased distal strength in both lower extremities (grade $3 / 5$ dorsiflexion, grade 2/5 planterflexion, grade $1 / 5$ inversion and eversion), with decreased sensation in the $\mathrm{L} 5$ and $\mathrm{S} 1$ distribution and absent Achilles response. A full spine MRI revealed mixed signal abnormalities in the thoracolumbosacral spinal canal representing a T12-S1 syrinx with septations, a tethered cord, and thickened filum terminale [Figure 1]. With contrast, there was only mild enhancement seen at the L3-4 level. At the S2-3 levels, there was a Tarlov cyst that contributed to scalloping of the vertebral bodies; it was isointense on $\mathrm{T} 1$ and hyperintense on T2 MRI, did not enhance, and measured $50 \times 40 \times 19 \mathrm{~mm}$.

\section{Surgery}

During surgery, a L3-4 laminectomy revealed thinned-out dura, and a midline myelotomy decompressed the syringomyelia and revealed a gliotic encysted space occupying lesion that was biopsied [Figure 2]. In addition, through a Sl-2 laminectomy, the filum terminale was divided, allowing for dithering of the cord and its proximal migration [Figure 3]. Furthermore, the Tarlov cyst was fenestrated (e.g., cyst fluid was removed along with part of the cyst wall, whereas surgical clips obliterated the communication between the subarachnoid space and the cyst) [Figure 3].

\section{Neurological examination postoperatively}

By the $3^{\text {rd }}$ postoperative day, the patient's distal strength improved to the $4-/ 5$ level on the left side and $4+/ 5$ level on the right side; pain was relieved and sphincter control improved. Two weeks later, the patient was ambulated with minimal support, and sphincter function and his neurological exam normalized.

\section{Histopathology}

Pathologically, the gliotic space occupying lesion at the L3-4 level was an ependymal cyst. It was lined by cuboidal cells with rounded uniform nuclei, inconspicuous nucleoli, and eosinophilic cytoplasm. Glial tissue was identified just underneath these cells and immunohistochemical stain was positive for S-100 protein and glial fibrillary acidic protein (GFAP), however, it was negative for cytokeratin AEl/AE3 and epithelial membrane antigen.

\section{DISCUSSION}

Diagnosis and treatment of tethered cord syndrome

In the absence of any history of spinal dysraphism, adults presenting with TCS are rare. MRI demonstrates a thickened, posteriorly displaced filum terminale (>2 mm), often with a low lying conus usually below the $\mathrm{L} 2$ vertebral body. ${ }^{[5]}$ Early and aggressive surgical intervention is recommended in symptomatic patients, owing to $80 \%$ improvement in pain, $60 \%$ improvement

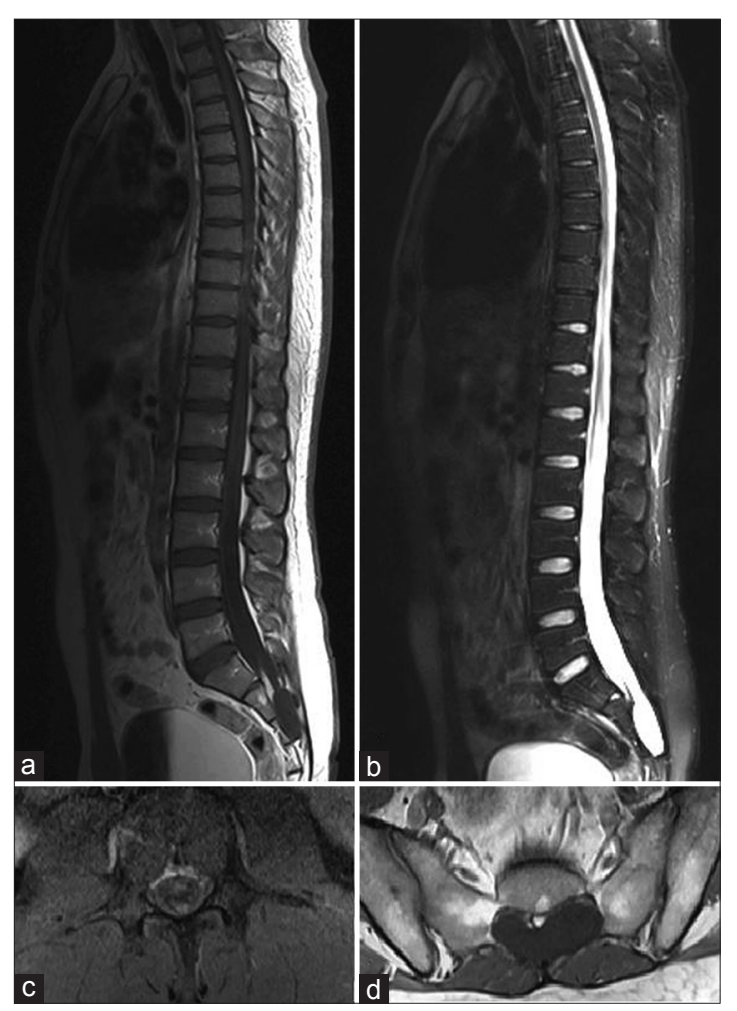

Figure I: Preoperative (a)T I and (b)T2-weighted sagittal magnetic resonance imaging (MRI) showing mixed signal abnormalities representing syringomyelia with septations extending from TI2 to SI levels, alongside cord tethering and thickening of the filum terminale at the S2 level. Another signal abnormality seen at S2-3 level causing scalloping of the vertebral bodies - isointense on TI (a) and hyperintense on T2 (b), representing a Tarlov cyst. TI-weighted axial cuts at the L3-4 level (c) highlighting contrast enhancement of a solid component with gadolinium and enlargement of the spinal canal at the S2 level by the Tarlov cyst (d) 

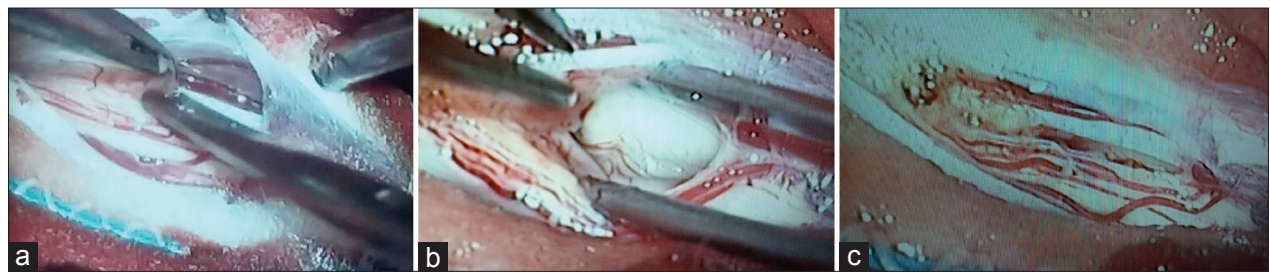

Figure 2: (a) Observation of a very thinned out dural layer after laminectomy as depicted on durotomy. (b) A midline myelotomy was performed to decompress the syrinx. (c) Closer inspection revealed a yellow colored gliotic encysted space occupying lesion at the caudal end of the myelotomy
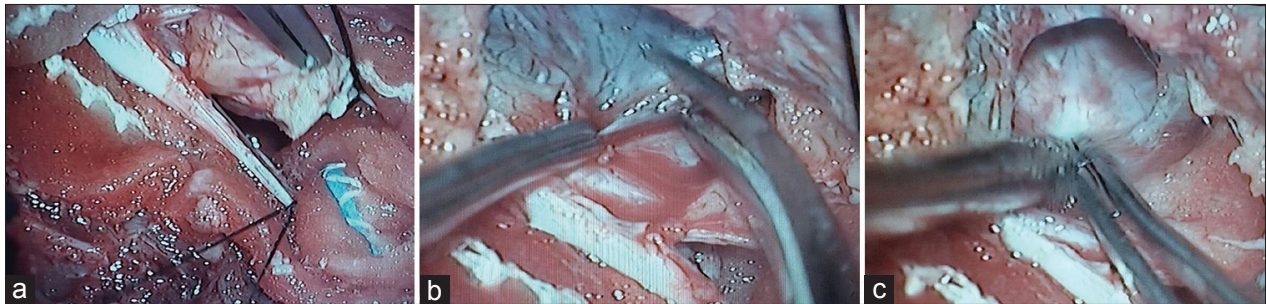

Figure 3: (a) Represents the thickened filum terminale observed after SI-2 laminectomy, which was divided to untether the cord. (b) The picture shows the relation of the Tarlov cyst with the durotomy (proximal) done for un-tethering. (c) Represents the fenestration of the Tarlov cyst with evacuation of fluid and partial removal of the cyst wall

in motor deficits, and $50 \%$ tendency for improvement in sensory and urinary symptoms. ${ }^{[2]}$

Diagnosis and treatment of ependymal cysts Ependymal cysts and particularly intramedullary spinal cysts are rarely encountered in the adult spine. As in the case presented here, patients may present with pain, motor, sensory, and sphincter dysfunction. ${ }^{[6]}$ MRI scans typically demonstrate smooth and well-defined borders that are isointense on $\mathrm{T} 1$ and $\mathrm{T} 2$ studies and do not enhance. Immunohistochemical staining is often necessary to establish the diagnosis (e.g., these cysts are positive for both the glial markers expressed by normal ependymal epithelium - GFAP and S-100). ${ }^{[6]}$ Surgery of intramedullary lesions typically includes partial resection, biopsy, cyst-subarachnoid shunt, cyst fenestration, and marsupialization, and often leads to neurological improvement. These cysts rarely recur.

\section{Tarlov cyst management}

The optimal management of symptomatic Tarlov cysts is controversial. Surgical options include lumbar CSF drainage, lumbar peritoneal shunt, cyst subarachnoid shunt, CT-guided percutaneous aspiration of the cyst, with or without infusion of fibrin glue, laminectomy for decompression of cyst, partial cyst removal with neck ligation or wall imbrication, and microsurgical fenestration of cyst to the thecal sac. Varying rates of symptom resolution, cyst recurrence, and postoperative complications have been reported..$^{[1,4]}$ In this case, the cyst was fenestrated and surgical clips were utilized to close the opening.

Financial support and sponsorship Nil.

\section{Conflicts of interest}

There are no conflicts of interest.

\section{REFERENCES}

I. Acosta FL Jr, Quinones-Hinojosa A, Schmidt MH, Weinstein PR. Diagnosis and management of sacral Tarlov cysts. Case report and review of the literature. Neurosurg Focus 2003; I5:EI5.

2. Lee GY, Paradiso G, Tator CH, Gentili F, Massicotte EM, Fehlings MG. Surgical management of tethered cord syndrome in adults: Indications, techniques, and long-term outcomes in 60 patients. J Neurosurg Spine 2006;4:|23-3|.

3. Park CH, Hyun SJ, Kim KJ, Kim HJ. Spinal intramedullary ependymal cysts: A case report and review of the literature. J Korean Neurosurg Soc 20I2;52:67-70.

4. Paulsen RD, Call GA, Murtagh FR. Prevalence and percutaneous drainage of cysts of the sacral nerve root sheath (Tarlov cysts). AJNR Am J Neuroradiol 1994; I5:293-7.

5. Raghavan N, Barkovich AJ, Edwards M, Norman D. MR imaging in the tethered spinal cord syndrome. AJR American journal of roentgenology 1989; 152:843-52.

6. Saito K, Morita A, Shibahara J, Kirino T. Spinal intramedullary ependymal cyst: A case report and review of the literature. Acta Neurochir 2005; 147:443-6. 